\title{
Author Correction: The ultrafast X-ray spectroscopic revolution in chemical dynamics
}

Peter M. Kraus, Michael Zürch, Scott K. Cushing, Daniel M. Neumark (1) and Stephen R. Leone $\mathbb{D}$

Nature Reviews Chemistry (2018) https://doi.org/10.1038/s41570-018-0008-8 Published online 29 May 2018

In the original version of the article the authors inadvertently omitted to acknowledge funding from the U.S. Department of Energy, Office of Science, Office of Basic Energy Sciences, Gas Phase Chemical Physics Program under contract no. DE-AC02-05-CH11231. This has been corrected in all versions of the published article.

https://doi.org/10.1038/s41570-018-0016-8 I Published online 14 June 2018 